\title{
EXTRUSION FLOW DEMONSTRATED BY BORE-HOLE DEFORMATION MEASUREMENTS OVER A RIEGEL, STORGLACIÄREN, SWEDEN
}

\author{
By Roger leB. Hooke, * Per Holmlund, \\ (Naturgeografiska Institutionen, Stockholms Universitet, Stockholm, Sweden) \\ and NEAL R. IVERSON
}

(Department of Geology and Geophysics, University of Minnesota, Minneapolis, Minnesota 55455, U.S.A.)

ABSTRACT. Inclinometry measurements in a $126 \mathrm{~m}$ bore hole slightly down-glacier from the crest of a riegel on Storglaciären showed what appears to be indisputable extrusion flow during the last 3 weeks of July 1984. The velocity at the bed was about five times that at the surface, and lay in a direction deviating $50-60^{\circ}$ from that at the surface. The increase in velocity with depth began more than $50 \mathrm{~m}$ above the bed. In August and the first half of September the flow returned nearly to "normal" with only a slight tendency toward extrusion. The flow in July appeared to be related to a period of large diurnal water-pressure variation and cavity opening at the bed up-glacier from the riegel. Decoupling of the ice from the bed on the lowest parts of the riegel may have permitted the extrusion. The return to more "normal" conditions in August appears to have been related to a decrease in ice flux over the riegel and a widening of the zone of decoupling.

\section{INTRODUCTION}

The term "extrusion flow" was apparently first used by Demorest (1941, 1942), who suggested that ice became more plastic with depth and might therefore flow faster. Nye (1952) showed that such flow was impossible under normal circumstances, in which the glacier is wide and bed irregularities small compared with the ice thickness. This is because a surface layer of ice that was being dragged outward by shear stresses exerted on its bottom by fastermoving deeper ice as well as pushed outward by imbalanced hydrostatic forces resulting from the down-glacier surface slope would not be in static equilibrium. The term has thus vanished from the literature, for the most part, and we reintroduce it with some reluctance. However, we have measured flow similar to that originally hypothesized by Demorest and, rather than coin a new term to describe it, we have chosen to resurrect the old term, with the understanding that all available evidence suggests that such flow is only possible in situations where a special valley geometry and perhaps temperature regime result in static equilibrium of the surface layer, despite the additional down-glacier shear force on its bottom.

The bore hole in which the present measurements were made is slightly down-glacier from the crest of a riegel in the bed of Storglaciären, northern Sweden (Fig. 1). The riegel is at the down-glacier end of an overdeepened area in the bed. Radio-echo measurements (Björnsson, 1981) suggested that the threshold of the riegel is more than $70 \mathrm{~m}$ above the deepest part of the overdeepened area. However, subsequent drilling indicates that over the riegel, though not elsewhere, the ice thickness is systematically 5-10 m greater than implied by the radio-echo data. Down-glacier from the riegel the maximum ice thickness remains relatively constant for about $300 \mathrm{~m}$, as the ice descends into another

*Permanent address: Department of Geology and Geophysics, University of Minnesota, Minneapolis, Minnesota 55455, U.S.A. overdeepened area, and then thins abruptly over a second riegel. We think that the extrusion flow is a result of a complicated stress configuration resulting from these bed irregularities, and also involving local decoupling of the glacier from its bed due to high water pressure and cavity formation.

In addition to the bore-hole deformation measurements, we have data on surface velocity and strain-rates in the vicinity of the bore hole and on water-pressure variations in nearby holes. Our principal intention in this paper is to present the data available. A full explanation of the observations will probably require a detailed threedimensional analysis of the stress distribution, and is impractical at this stage.

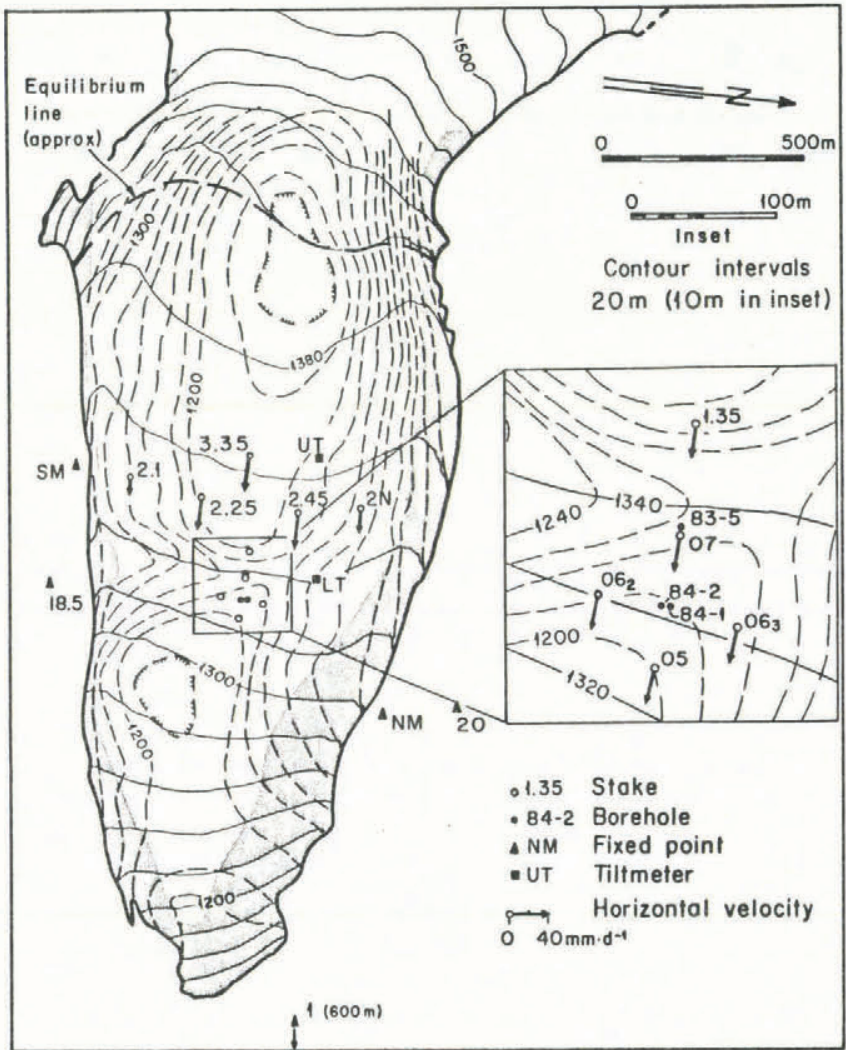

Fig. 1. Map of Storglaciären showing surface topography as of 1969 (solid contours); bed topography obtained by radio-echo techniques in 1979 (Björnsson, 1981), using the 1969 topography as a reference (dashed contours); location of the bore hole used for inclinometry measurements (84-2), and of other bore holes used for water-pressure measurements (84-1 and 83-5); and mean annual horizontal velocities of several stakes in the vicinity of the hole. Ice is less than $40 \mathrm{~m}$ thick in shaded areas along glacier sides and thus probably frozen to the bed. 


\section{MEASUREMENTS}

The bore hole in question was drilled with a hot-water drill, and its deformation was measured with a Slope Indicator Company (Seattle, WN) model 50325 biaxial inclinometer. The digital read-out on the inclinometer gives twice the sine of the angle of deviation from the vertical to four decimal places. The inclinometer runs in tracks on the inside of an extruded cylindrical plastic casing. The tracks keep the instrument aligned across one of two mutually perpendicular diagonals of the casing. During a single run down the hole, the inclination of the casing can be measured on both diagonals, as there are two sensors in the instrument mounted at right-angles to one another. By turning the inclinometer through $180^{\circ}$ and making a second run, errors due to inaccurate zero setting of the instrument are eliminated. Our standard procedure during a survey actually involved four runs down the hole so there is a four-fold redundancy in the data. That is, we have two measurements at each depth with the inclinometer in one orientation and, knowing the error in the zero setting from other measurements, can estimate the same values from the measurements with the inclinometer rotated $180^{\circ}$. Thus the occasional bad measurement, due to inaccurate depth control or transcription error, can be discarded. Measurements are made at $1 \mathrm{~m}$ depth intervals.

The hole was bored on 3 July, cased the next day, and first measured on 10 July, thus leaving a few days for the casing to stabilize in the hole. Subsequent inclinometry surveys were made on 17 July, 31 July, 17 August, and 11 September. The velocity profiles derived from these measurements are shown in Figure 2.

The manufacturer of the inclinometer estimates that, if measurements are made at $0.5 \mathrm{~m}$ intervals (instead of the
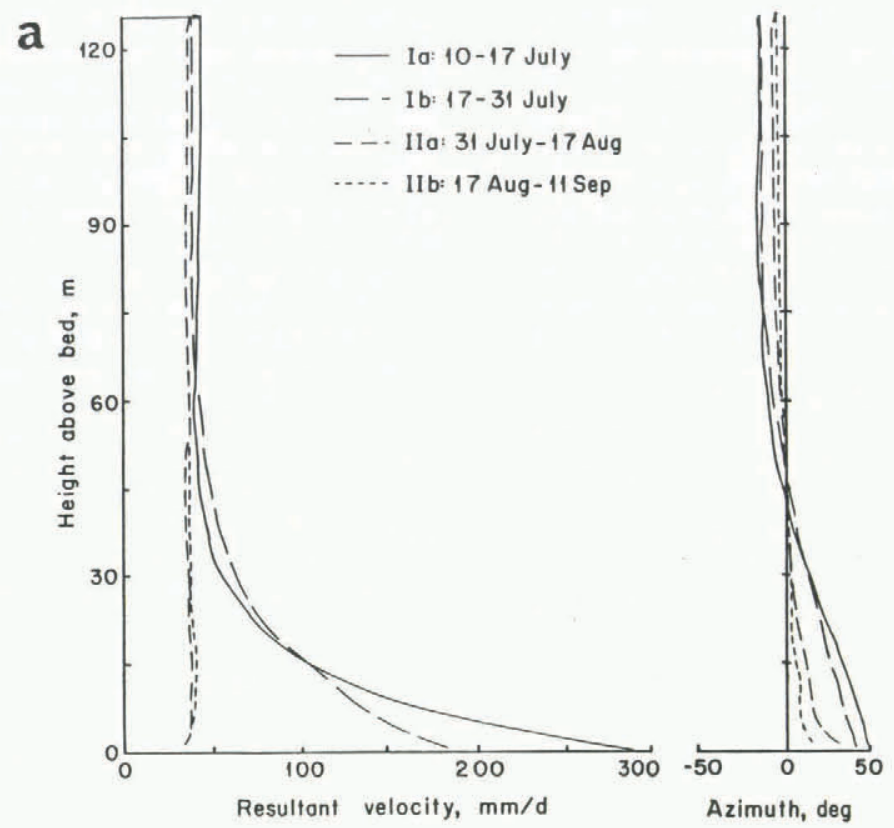

b

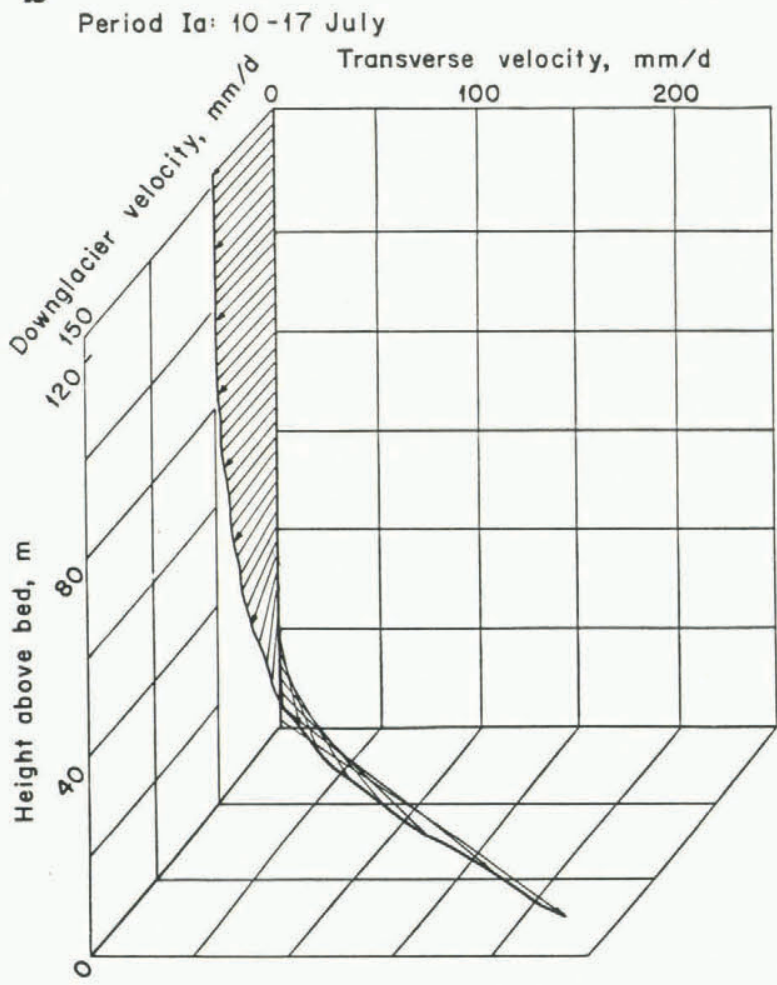

Ib: $17-31$ July

IIa: 31 July-17 Aug

II b: 17 Aug -11 Sep
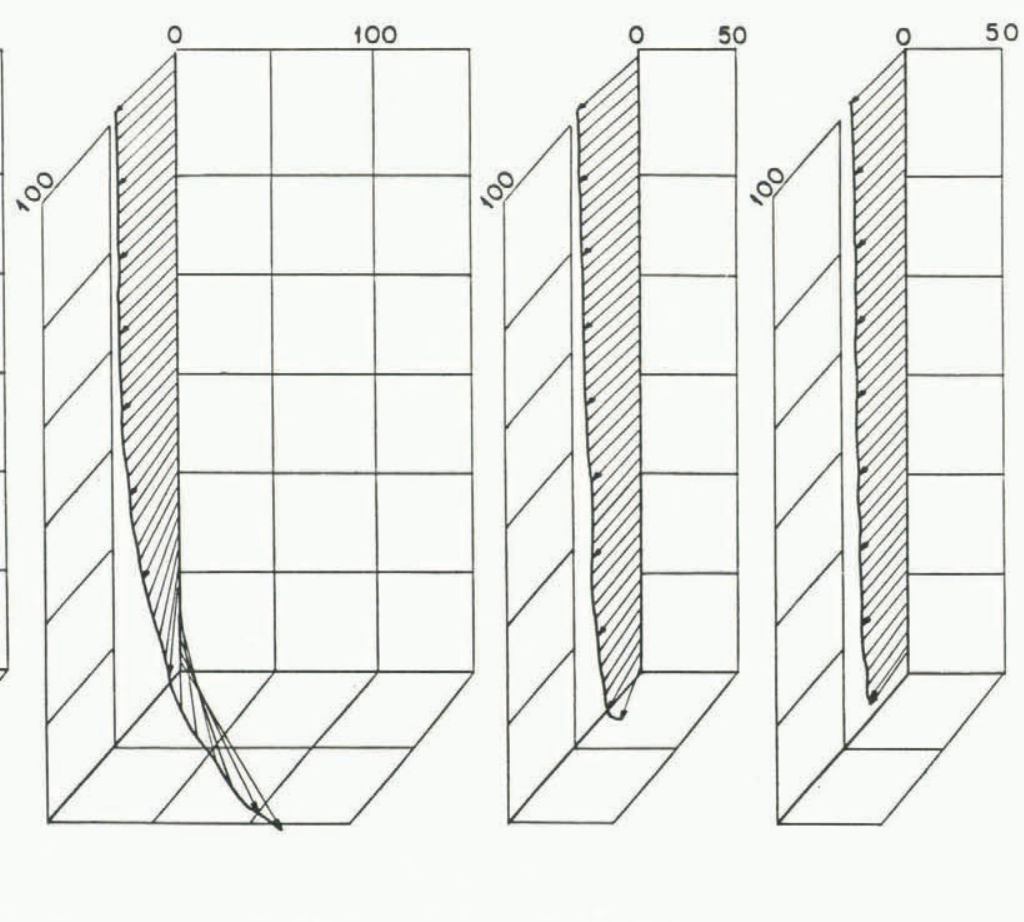

Fig. 2. Velocity profiles derived from bore-hole deformation measurements.

a. Resultant velocity and azimuth expressed as deviation from mean.

b. Perspective plots of profiles. 
$1 \mathrm{~m}$ intervals we used) and if only one set of measurements is made in each track, the uncertainty in the position of the bottom of the casing with respect to the top should be $\pm 16 \mathrm{~mm}$ in a hole such as ours. We conducted an error analysis using the repeated measurements in the same track to estimate the standard error in a single measurement, and assuming that errors were distributed randomly. This analysis suggested an uncertainty of less than $5 \mathrm{~mm}$. To this should be added uncertainties resulting from inaccurate measurement of depth and from use of measurements made with a $0.5 \mathrm{~m}$ long instrument to infer the average inclination of a section of casing $1 \mathrm{~m}$ long. We have not made a formal estimate of the contribution of these sources of error but, based on comparison with the above estimate by the manufacturer, a total uncertainty of $\pm 20 \mathrm{~mm}$ seems reasonable. There is, however, an additional larger uncertainty due to possible movement of the casing independently of the ice, as the ice probably did not close tightly around the casing in the lower part of the hole during the period of the experiment. Assuming that the hole diameter was three times the casing diameter, this might account for an error in our estimate of the relative displacement of the ice at the surface with respect to that at the bottom of $\pm 20 \mathrm{~mm} / \mathrm{d}$ between the first two surveys. Later, the casing should have stabilized in the hole and the time invervals between surveys were longer so the uncertainty from this source should be less. Clearly, errors from these sources cannot explain the bizarre results obtained, and we have not identified other sources of error that could.

One possible source of error that was excluded early in the study was incorrect recording of the track in which the inclinometer was lowered into the hole. This was excluded because: (1) a day or two after the 17 July survey the instrument was lowered a few meters down the hole and its orientation and inclination carefully checked against the notes from the earlier surveys; (2) readings on a given

\section{A. Horizontal velocity}

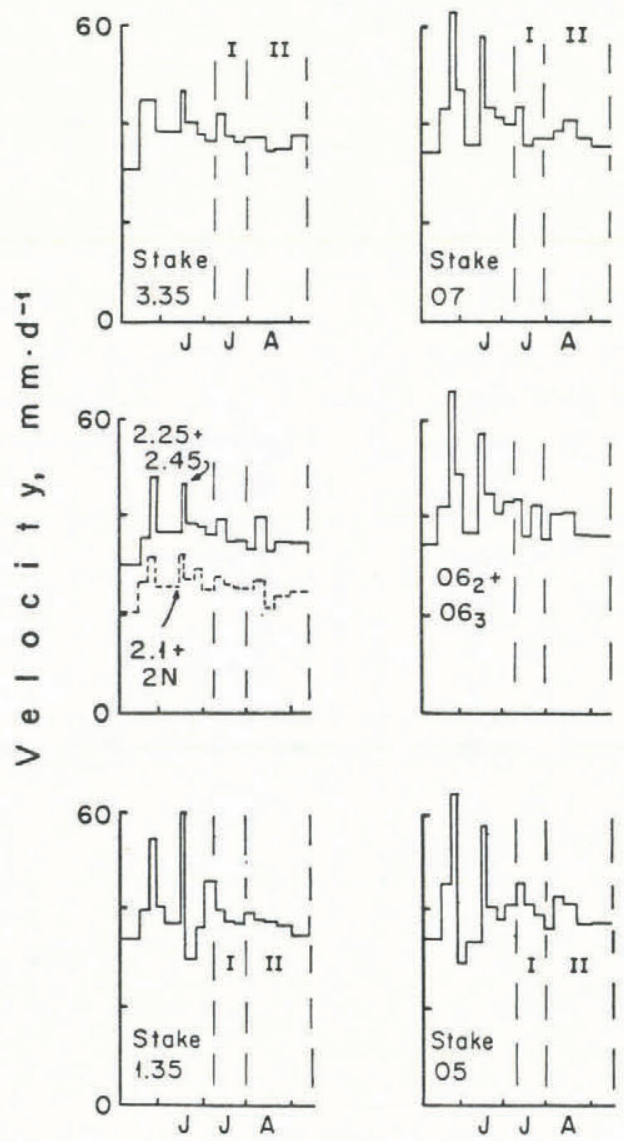

diagonal of the casing are sufficiently similar from one survey to the next and sufficiently different from those on the other diagonal to make it impossible to mix diagonals between surveys; and (3) if the instrument orientation in one or both diagonals was off by $180^{\circ}$, ice flow at the bed would have appeared to have been up-glacier, which would be even more difficult to explain.

In the location of the bore hole, radio-echo measurements indicated an ice thickness of about $118 \mathrm{~m}$. The total amount of hose used in drilling the hole, including the guide tube and nozzle, was $126 \mathrm{~m}$. However, the hose, which was made of rubber, stretched about $12 \%$ at the surface. Assuming an average stretch of $6 \%$ gives a depth of between 133 and $134 \mathrm{~m}$. The total length of casing inserted was $131.6 \mathrm{~m}$. This is close enough to the latter measurements that we assume the casing reached the bottom of the hole. The stretching of the hose made it difficult to sense exactly when the drill stopped, but the nozzle was kept at its maximum depth for several minutes so we assume that the hole either reached the bed or, at worst, bottomed on a large englacial rock quite near the bed. Numerous other bore holes within $50 \mathrm{~m}$ of the cased hole, some of which were drilled with a light-weight plastic hose that had negligible stretch, all indicated a bottom within a few meters of the $131.6 \mathrm{~m}$ figure. After correcting for inclination of the hole, the total ice thickness turns out to be between 125 and $126 \mathrm{~m}$.

During the last 3 years, measurements of horizontal and vertical velocity have been made on a network of 32 stakes covering much of Storglaciären. Ten of these stakes are shown in Figure 1, and staircase diagrams of velocities are given in Figure 3. The stakes were being surveyed at approximatey weekly intervals during the time period covered by the bore-hole deformation study. The surveys involved measuring the distances to two fixed points on the valley sides (Fig. 1) with an electronic distance meter and measuring the vertical angle to the stakes from a third

\section{B. Vertical velocity}
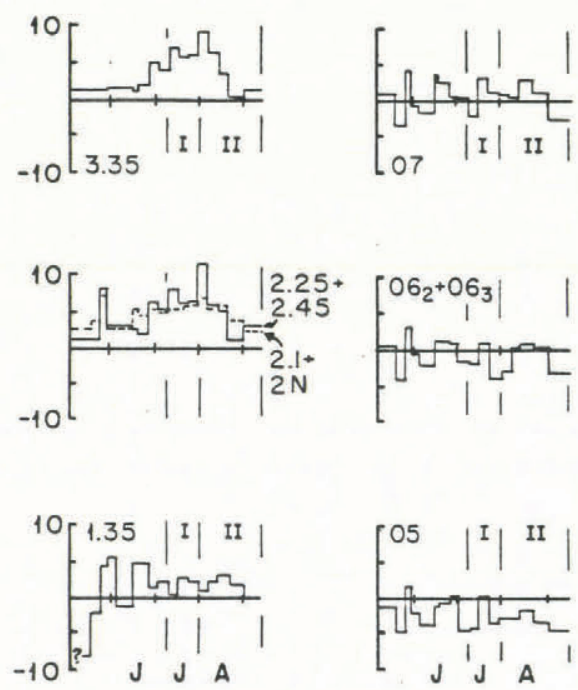

Fig. 3. Horizontal and vertical velocities of ten stakes in vicinity of bore hole. I and II refer to time periods discussed in text. Stake locations are shown in Figure 1. 
fixed point. The procedure differs from that described previously (Hooke and others, 1983) only in the location of some of the fixed points used for five of the stakes. Surface strain-rates were determined from deformation of the nets formed by stakes $1.35,2.25,2.45$, and 3.35 (net 1.35 ) and by stakes $05,06_{2}, 06_{3}$, and 07 (net 05), using the method described by Nye (1959). The results are shown in Figure 4. A detailed analysis of the uncertainty in velocities and strain-rates has been given in Hooke and others (1983) and will not be repeated here. Suffice it to say, the standard errors are believed to be $\pm 1.5 \mathrm{~mm} / \mathrm{d}$ in horizontal velocity and $\pm 2 \mathrm{~mm} / \mathrm{d}$ in vertical velocity for measurements made $7 \mathrm{~d}$ apart. The corresponding uncertainty in strainrates is $\pm 0.008 \mathrm{a}^{-1}$.

Water-pressure variations were being recorded in four bore holes and two moulins in the vicinity of the hole used for inclinometry measurements. Results from two of the bore holes are shown in Figure 5. Standard automobile oilpressure gauges were used for the measurements. There is a hysteresis in these gauges, resulting in an uncertainty in water depth of about $\pm 2 \mathrm{~m}$. In addition, the gauges used had a pressure range of either $0.5 \mathrm{MPa}$ or $1 \mathrm{MPa}$ and water-pressure variations often exceeded these amounts. Thus, in order to record maximum water levels, gauges were generally not placed at the very bottoms of the holes. In one case, a fortuitous placement of gauges resulted in water pressures between 31 and $73 \%$ of the ice-overburden pressure being recorded in one hole (83-5) and pressures above $50 \%$ of the overburden pressure being recorded in another (84-1). The two curves match well in the region of overlap (Fig. 5). Of the other two holes, one did not appear to be connected to the subglacial water system for much of the season and the other gave results comparable to those shown in Figure 5. The moulins were up-glacier from the riegel and the transducers in them were only $\sim 40 \mathrm{~m}$ below the glacier surface. They thus recorded only the highest water levels which, however, generally coincided with high water levels in the bore holes.

Two Westfall Tiltmeters were in operation for $3-6 \mathrm{~d}$ at the end of July. These instruments, which have precisions of approximately $\pm 1 \mu \mathrm{rad}$, monitor changes in slope of the glacier surface resulting, for example, from differential

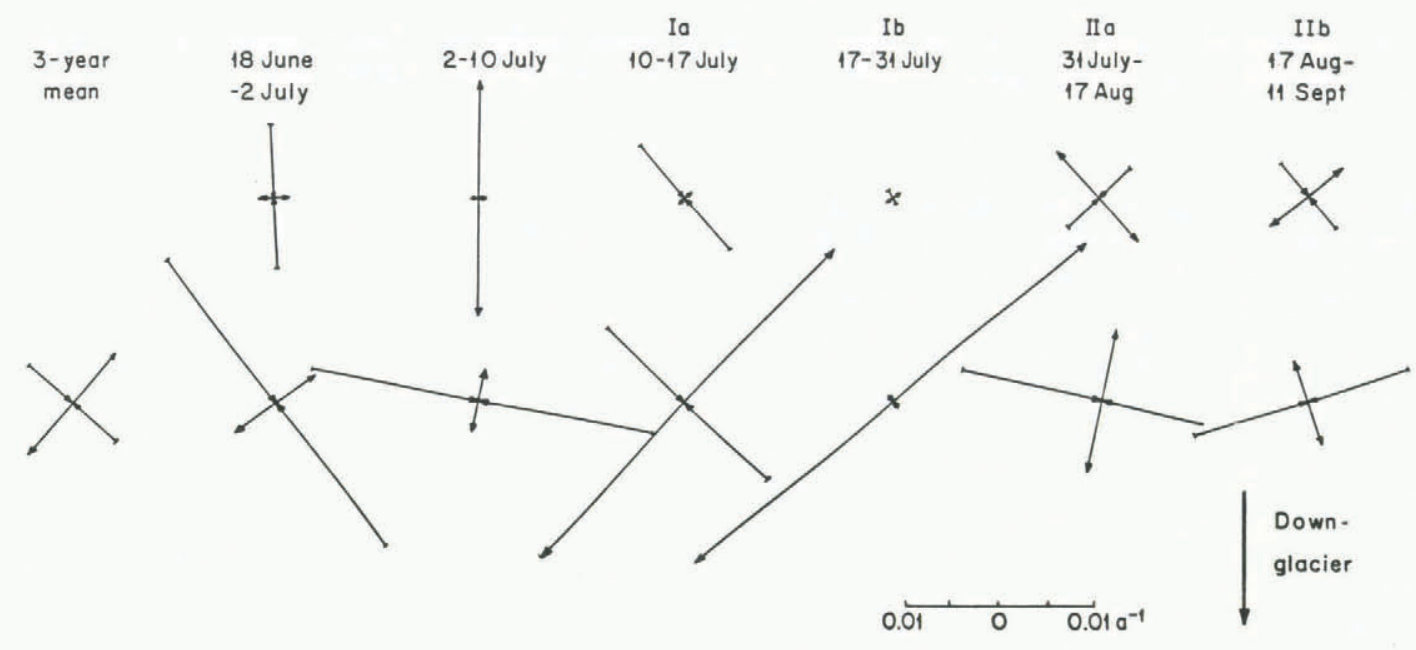

Fig. 4. Strain-rates in strain net 1.35 up-glacier from the riegel and strain net 05 surrounding the bore hole. Long-term average strain-rates are shown at the left.

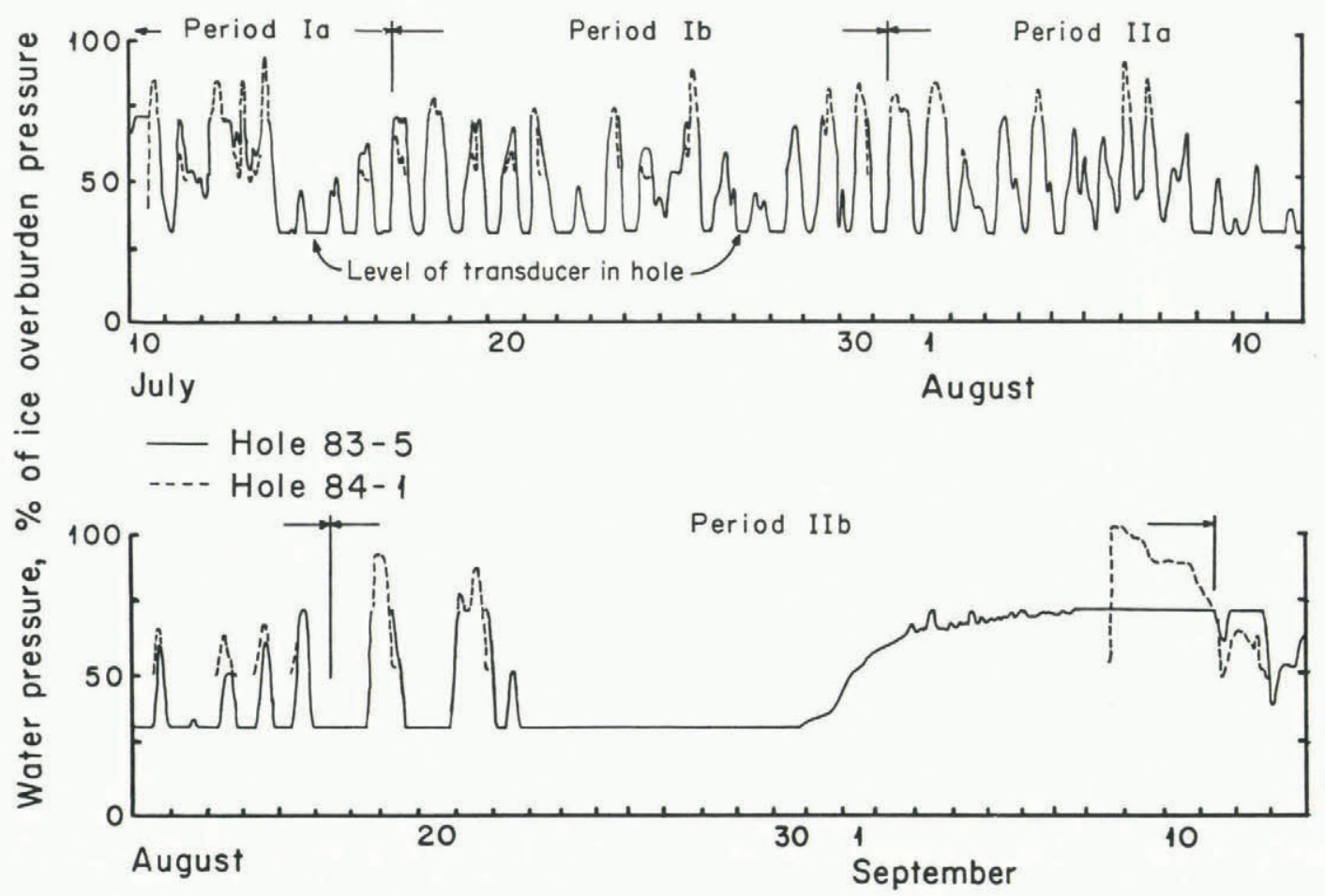

Fig. 5. Water-pressure variations in bore holes. See text for discussion of relation between dashed and solid lines. Hole locations are shown in Figure 1. 


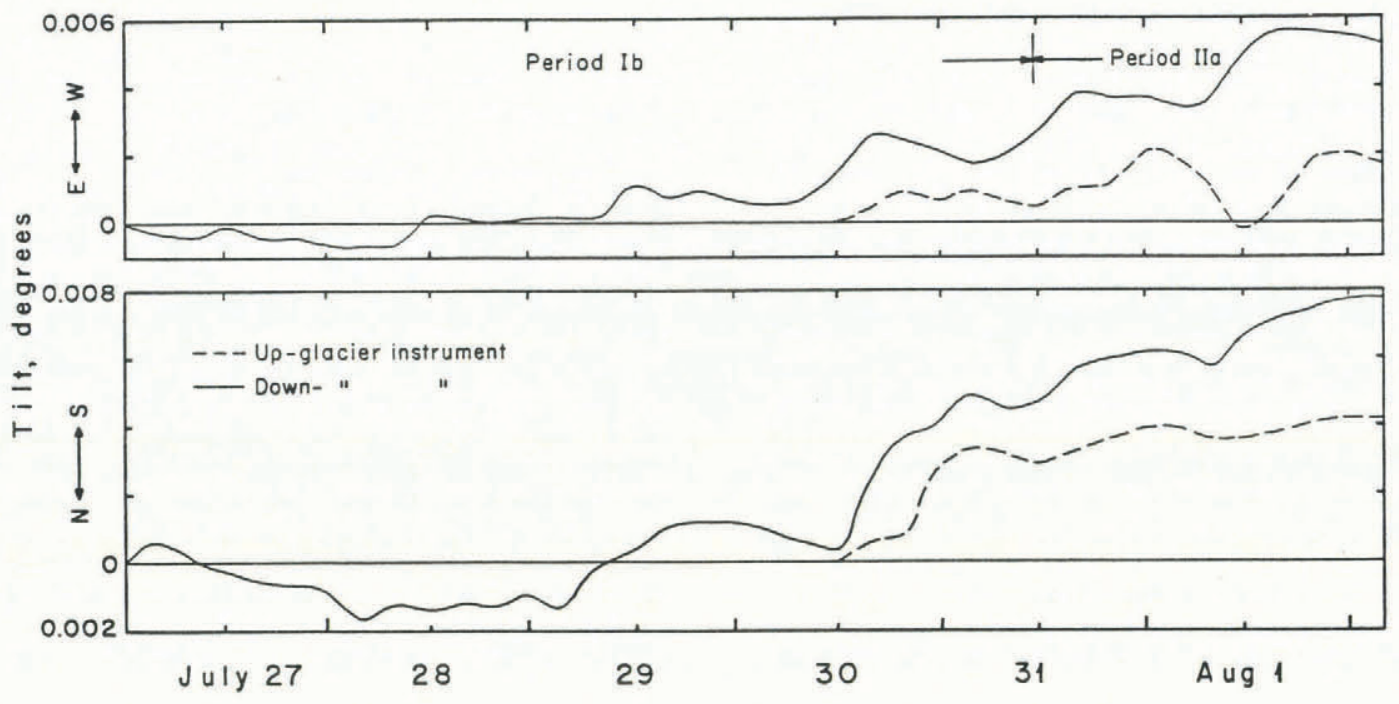

Fig. 6. Tiltmeter records. Note the change from a fairly stable or slightly northerly tilt to a dominantly south-westerly tilt about $30 \mathrm{July}$ in the record from the down-glacier meter.

uplift of the center of the glacier with respect to the margin. The meters were located somewhat up-glacier from the inclinometered hole and about $100 \mathrm{~m}$ north of the glacier center line (Fig. 1). They appear to record a change from a stable or possibly slightly northerly tilt to a southwesterly tilt near the end of the period of strong extrusion flow (Fig. 6). Unfortunately, electrical storms repeatedly disabled the instruments (which have now, however, been modified to protect against such damage), thus limiting the period of record.

A final point of possible importance is that the temperature of the glacier is below the pressure meltingpoint to a depth of $35-40 \mathrm{~m}$ (Schytt, 1955, 1968; unpublished data). Thus, it should be frozen to the bed along the valley sides where the thickness is less than this (Fig. 1).

\section{CALCULATION OF CAVITY-OPENING SPEED}

The relation

$$
w_{\mathrm{c}}=w-u \tan \beta-\left\langle\dot{\varepsilon}_{\mathrm{z}}\right\rangle H
$$

has been used to calculate what we infer to be the rate of opening of cavities at the glacier bed, $w_{c}$ (Hooke and others, 1983). In this equation $u$ and $w$ are the mean vertical and horizontal velocities of the four stakes in a strain net, $\boldsymbol{\beta}$ is the bed slope, taken to be positive when the bed slopes upward in the down-glacier direction, and $\left\langle\dot{\epsilon}_{z}\right\rangle$ is the mean vertical strain-rate over the ice thickness $H . \quad u$ and $w$ are known from surface-velocity surveys, $H$ and $\beta$ are known from radio echo-sounding data, and $\left\langle\dot{\epsilon}_{z}\right\rangle$ is obtained from the surface strain-rates assuming that strain-rates in the horizontal plane are independent of depth (see Hooke and others (1983) for a discussion of this assumption).

Our previous calculations using this relation were quite "successful" in the sense that integration of $w_{c}$ over time suggested that cavities began to open in mid July, reached their maximum size in mid August, and then closed to very close to their original size the following June. In those calculations a $4 \times 5$ grid of twenty stakes, forming 12 square strain nets, was used. The present calculations have not been as "successful", as cavities do not appear to return to their original sizes in early summer each year. This is attributed to lack of good control on $B$ in this area where the bed topography is more irregular. However, if cavity size is plotted against time, a line can be drawn tangent to the local minima and used as an estimate of the zero base line from which cavity size is measured (Fig. 7). When this is done, cavities again appear to go through an annual cycle

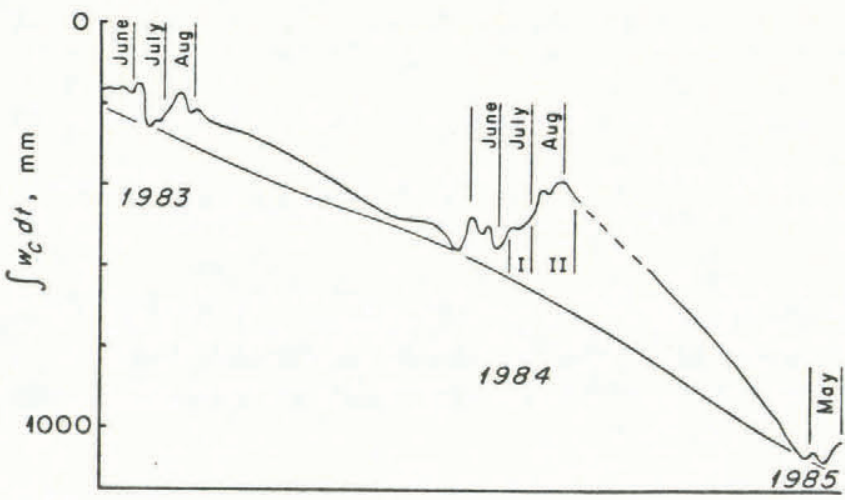

$+\mathrm{i} \mathrm{me}$

Fig. 7. $\int w_{c} d t$ plotted against time for strain net 1.35. The difference between the curve and the line tangent to local minima is considered to be an estimate of the mean height of cavities at the bed (see text).

with minima in early summer and maxima about 2 months later. The slope of such a tangent line divided by the horizontal velocity can be interpreted as an estimate of the error in $B$. In net 1.35 , the resulting error is $\sim 1.5^{\circ}$, which is reasonable in view of the uncertainty in determining what constitutes a mean slope under such a strain net. In net 05 , however, it was $12^{\circ}$. This may be due, in part, to the previously mentioned discrepancy between the radio-echo measurements of ice thickness over the riegel and the thickness obtained by drilling. However, as discussed further below, $\dot{\epsilon}_{z}$ probably increased with depth during the period of extrusion flow. Thus, use of the value at the surface as an estimate of the average value over the ice thickness would have resulted in overestimating $w_{\mathrm{c}}$.

\section{DISCUSSION}

For purposes of discussion, we consider two periods: period I from 10 to 31 July with marked extrusion flow, and period II from 31 July to 11 September with negligible extrusion flow, and seek other differences between these two periods capable of explaining the difference in internal flow character. Each of the periods is further subdivided into intervals "a" and " $\mathrm{b}$ " to coincide with the time period between inclinometer surveys (Fig. 2).

Surface velocities do not help. The highest horizontal velocities occurred during two periods of unseasonably warm 
weather in late May and mid June (Fig. 3). By the time of the bore-hole deformation measurements, velocities had decreased substantially from these peaks. In strain net 05 during period Ia (10-17 July; Fig. 3), horizontal velocities seem to have been somewhat higher and vertical velocities more downward, but there are no obvious differences between period Ib and period II. In net 1.35 , period I was a time of steadily increasing vertical velocity, apparently reflecting cavity opening at the bed (Fig. 7).

An attempt was made to use the velocity data to calculate an ice-mass balance between the $2.1 \rightarrow 2 \mathrm{~N}$ transverse profile and the $06_{2} \rightarrow 06_{3}$ profile to see if the extrusion flow, estimated to be about $200 \mathrm{~m}^{3} / \mathrm{d}$, could be detected. However, the data are too sparse and the uncertainty in the measurements too large to make such a calculation, particularly when subglacial cavity-size variations are considered.

The most important differences between periods I and II appear to be in strain-rate, cavity-opening rate, tilt direction, and water pressure. The 3 week period prior to initiation of the bore-hole deformation measurements was characterized by longitudinal compression followed by extension in strain net 1.35 and by rather strong compression along a north-east to south-west axis, roughly parallel to the extrusion flow, in net 05 (Fig. 4). In both nets, strainrates were substantially higher than the long-term means (shown at the left in Figure 4). During period I, the northeast to south-west compression in net 05 died out, but high extending strain-rates developed approximately normal to the direction of extrusion flow. Then, during period II, the orientation of the principal strain-rates changed so that the strain was extending in the down-glacier direction and compressive in the transverse direction. In net 1.35, the changes in strain-rate between periods I and II do not appear to be significant, considering the uncertainty in the measurements. However, cavities seem to have been comparatively small and opening rather rapidly beneath this net during period I (Fig. 7), whereas during period II they were significantly larger and, except during the first week of period IIa, were either opening more slowly or beginning to close again.

As noted, the tiltmeters located on the north side of the glacier recorded a change from essentially no transverse tilting of the glacier surface at the end of period $\mathrm{Ib}$ to a southerly tilting at the beginning of period IIa (Fig. 6). A southerly tilt on this side of the glacier is the norm; it results from the fact that vertical velocities along the sides of the glacier are higher than on the center line. (This is a consequence of the convex-upward transverse profile, typical of the ablation area of all valley glaciers, which results in transverse extension on the center line and transverse compression nearer the valley sides (Raymond, 1971; Hooke and others, 1983, p. 267.) The lack of such southerly tilt during the last days of period $\mathrm{Ib}$ is thus anomalous. It suggests that the cavity-opening was taking place near the center line, thus increasing vertical velocities there.

Bore-hole water pressures showed a strong diurnal variation during period I (Fig. 5). The strength of this variation weakened during the first part of period II but the diurnal character persisted until 22 August. Between 23 August and 30 August, the water level was below the transducers in the holes. Then, between 31 August and 3 September, the water pressure in hole 83-5 increased and remained high for $10 \mathrm{~d}$. We tentatively interpret this increase to indicate that the hole had lost contact with the subglacial water system, or at least with the fluctuating part of this system. Between 8 and 12 September, water pressures also increased in the other holes and moulins; it appears that this may have re-established the connection between the subglacial system and hole 83-5, as water levels in this hole began to fluctuate again on 12 September.

In an attempt to quantify the water-pressure data, we calculated mean water pressures (expressed in terms of the local ice-overburden pressure) for the four time intervals of concern (Table I). Recognizing that the effect of water pressure on velocity is highly non-linear, we also calculated a weighted mean water-pressure effect, using an exponential function such that water pressures corresponding to, for example, $75 \%$ of the overburden pressure were weighted about 12 times as much as those corresponding to $50 \%$ of
TABLE I. WATER PRESSURE IN HOLES 83-5 AND 84-

\section{A. Mean water pressure in per cent of ice-overburden} pressure

$\begin{array}{lll}\text { Ia } & (10-17 \text { Jul. }) & 55.3 \\ \text { Ib } & \text { (17-31 Jul.) } & 47.1 \\ \text { IIa } & \text { (31 Jul. }-17 \text { Aug.) } & 45.4 \\ \text { IIb } & (17 \text { Aug. }-11 \text { Sep.) } & 43.7\end{array}$

B. Water pressures using exponential weighting function (see text)

$\begin{array}{llc}\text { Ia } & \text { (10-17 Jul.) } & 4.1 \\ \text { Ib } & \text { (17-31 Jul.) } & 2.1 \\ \text { IIa } & \text { (31 Jul. }-17 \text { Aug.) } & 2.0 \\ \text { IIb } & \text { (17 Aug. }-11 \text { Sep.) } & \text { Not meaningful }\end{array}$

the overburden pressure. These calculations serve to confirm that water pressures were higher, and their effect on velocity likely to have been greater during period I than period II, but they do not provide a clear distinction between the periods. This is consistent with the fact that the bore-hole deformation measurements suggest that the ice was effectively decoupled from the bed during both periods, in the sense that there is no apparent decrease in velocity near the bed in either period.

\section{CONCLUSION}

We now try to draw these diverse lines of evidence together into a unified picture of what may be happening over this riegel at the base of Storglaciären at this time of year. The increases in horizontal velocity and strain-rate in June (Figs 3 and 4), combined with the cavity-size data from this time period (Fig. 7), lead us to surmise that the ice became at least partially decoupled from the bed over a large area up-glacier from the riegel well before the borehole deformation measurements were initiated. We suspect that the north-east to south-west compression in strain net 05 in period Ia is due to drag exerted on the surface ice by the faster-moving basal ice; the occurrence of this compression in late June also suggests that the extrusion flow may have started at this time. Perhaps, the presence of the riegel, and possibly also the cold surface layer of the glacier, inhibits ice flow at the surface at this time of year, but decoupling of the ice from the bed over the lowest part of the riegel permits extrusion of basal ice. The asymmetry of the riegel, which is significantly more pronounced on the southern side of the glacier (Fig. 1), would have forced this basal ice towards the north-east.

The progressive decrease in north-east to south-west compression in strain net 05 during period I suggests that the extrusion velocity was initially greatest over the riegel and decreased down-glacier from it, as might be expected. With time, the extrusion appears to have become not only less pronounced (Fig. 2) but also more uniform under the net.

As cavities at the bed increased in size in late July, the zone of decreased basal friction may have become wider over the riegel. This is supported by the westward tilting indicated by the lower (but not the upper) tiltmeter during the first days of period IIa (Fig. 6) and by the observation that the horizontal velocity at stake 2.1 increased from an average of $61 \%$ of the center-line velocity during late June and early July to $77 \%$ of the center-line velocity during late July (period I). In addition, the subglacial drainage probably became better integrated, leading to lower water pressures, particularly in areas above the riegel, and hence lower horizontal velocities, on the average. The consequent changes in the stress field ended the extrusion.

\section{ACKNOWLEDGEMENTS}

Many people have contributed to the field effort required to assemble the diverse data reported in this paper P. Calla and K. Erikson had primary responsibility for the 
surface-velocity surveys; they were assisted by a number of other students. G. Johansson kept the drill running. K. Reece, B. Backman, and the late V. Schyttt contributed importantly to the physically comfortable and intellectually stimulating atmosphere at the Tarfala Field Station, which is run by the University of Stockholm for glaciological research.

The work is funded by the Swedish Natural Science Research Council and the U.S. National Science Foundation (grant DPP-8414190). The inclinometer was purchased with funds provided by the Wallenberg Foundation.

\section{REFERENCES}

Björnsson, H. 1981. Radio-echo sounding maps of Storglaciären, Isfallsglaciären, and Rabots glaciär, northern Sweden. Geografiska Annaler, Vol. 63A, Nos. 3-4, p. 225-31.

Demorest, M. 1941. Glacier flow and its bearing on the classification of glaciers. Bulletin of the Geological Society of America, Vol. 52, No. 12, Pt. 2, p. 2024-25.
Demorest, M. 1942. Glacier regimens and ice movements within glaciers. American Journal of Science, Vol. 240, No. 1, p. 31-66.

Hooke, R. LeB., and others. 1983. Seasonal variations in surface velocity, Storglaciären, Sweden, by R. LeB. Hooke, J. Brzozowski, and C. Bronge. Geografiska Annaler, Vol. 65A, Nos. 3-4, p. 263-77.

Nye, J.F. 1952. Reply to Mr. Joel E. Fisher's comments. Journal of Glaciology, Vol. 2, No. 11, p. 52-53.

Nye, J.F. 1959. A method of determining the strain-rate tensor at the surface of a glacier. Journal of Glaciology, Vol. 3, No. 25, p. 409-19.

Raymond, C.F. 1971. Flow in a transverse section of Athabasca Glacier, Alberta, Canada. Journal of Glaciology, Vol. 10 , No. 58 , p. 55-84.

Schytt, V. 1966. Notes on glaciological activities in Kebnekaise, Sweden during 1965. Geografiska Annaler, Vol. 48A, No. 1, p. 43-50.

Schytt, V. 1968. Notes on glaciological activities in Kebnekaise, Sweden during 1966 and 1967. Geografiska Annaler, Vol. 50A, No. 2, p. 111-20.

MS. received 16 June 1986 